\title{
Keeping Safe Online: Perceptions of Gulf Adolescents
}

\begin{tabular}{l|l|l|}
\hline Abdulmagni Mohammed Alqahtani' (D) & \\
\hline${ }^{1}$ Kingdom of Saudi Arabia & & \\
& & \\
\hline
\end{tabular}

\begin{abstract}
With an increasing number of young people across the Gulf States now having access to the internet, the online safety of these adolescents is of concern. In a survey of 115 adolescents from the Gulf States, it was found that, although there are many benefits to young people, the risks of online usage are not fully understood by teenagers or their parents. Perceptions of ways to keep safe online may be articulated, but the online behaviour of many youngsters seems to be at variance with their responses. The more sophisticated UK youngsters differ somewhat in their usage and this may be a path that Gulf adolescents take in future, therefore lessons may be learnt from the UK and other countries with longer online experiences.
\end{abstract}

Keywords: Adolescents, Online safety, Gulf states, Parental support

\section{Contents}

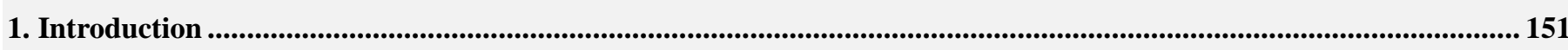

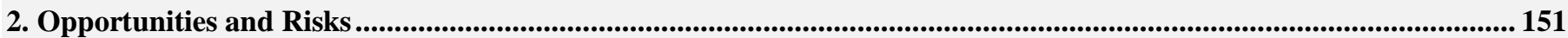

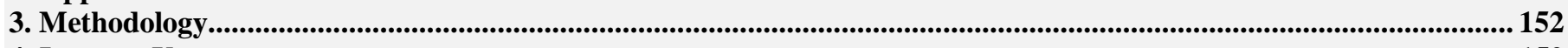

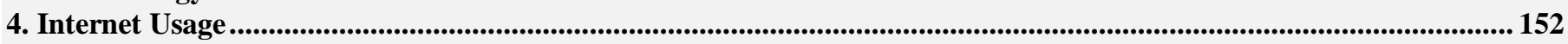

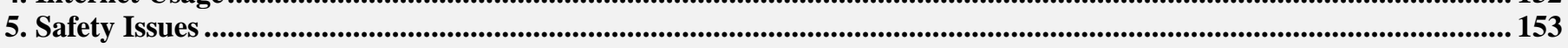

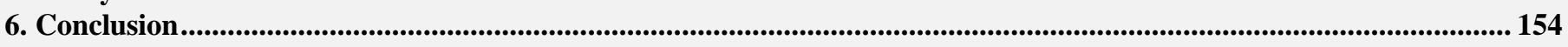

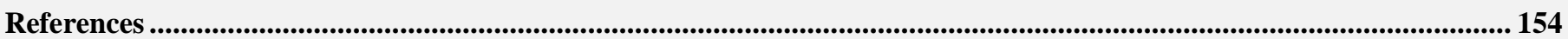

Citation | Abdulmagni Mohammed Alqahtani (2016). Keeping Safe Online: Perceptions of Gulf Adolescents. Journal of Education and e-Learning Research, 3(4): 150-155.

DOI:

$\operatorname{ISSN}(\mathbf{E})$ :

$\operatorname{ISSN}(\mathbf{P})$ :

Licensed:

Funding:

Competing Interests:

Transparency:

History:

Ethical:

Publisher: 10.20448/journal.509/2016.3.4/509.4.150.155 Crossref 2410-9991

2518-0169

This work is licensed under a Creative Commons Attribution 3.0 License $(\mathrm{cc}) \mathrm{EY}$

This study received no specific financial support.

The author declares that there are no conflicts of interests regarding the publication of this paper.

The author confirms that the manuscript is an honest, accurate, and transparent account of the study was reported; that no vital features of the study have been omitted; and that any discrepancies from the study as planned have been explained. Received: 24 November 2016/ Revised: 16 November 2016/ Accepted: 9 December 2016/ Published: 25 January 2017 This study follows all ethical practices during writing.

Asian Online Journal Publishing Group 


\section{Introduction}

There are many concerns for the safety of young people accessing the internet for social networking purposes. While the internet offers many benefits and opportunities for adolescents, it is also the source of many potential threats, including exposure to violence and pornography, vulnerability to attack and exploitation from adult predators, and cyberbullying from peers (Moreno et al., 2013). In the Gulf States (GCC) internet access and usage among adolescents has expanded dramatically over the past few years and internet safety is an area of growing concern for their parents, teachers and those with responsibilities for young people. This paper discusses the benefits and risks of social networking and investigates the online behaviours of adolescents from the Gulf States. It is particularly important to assess the impact of the internet on adolescents in the Gulf States, due to the volatility of the region and the vulnerability of young people being exposed to risks that are outside their cultural perceptions. In addition, the Gulf States represent a youthful population, where the median age is under 30, compared to the median age of 40 in the UK; this indicates that proportionately more young people in this region are going to be accessing the internet in future.

\section{Opportunities and Risks}

Lin and Lu (2011) study found that enjoyment was the most influential factor in people's continued use of social networking sites; this perceived enjoyment is reinforced by being able to expand social networks through online friends and relatives. Teenagers have reported that social media has a positive impact on their lives as it makes them more confident and helps them to develop friendships (Wallace, 2013) they also say that it makes them more popular and more sympathetic to others (Rideout, 2012). Jurgenson (2010) suggests that social networking platforms are so attractive because they offer participants personalised and user-generated content. This allows young people to identify with the content others are generating and build relationships. Ways in which adolescents in the Gulf States use social networking sites, and the benefits they see in such interactions, has not yet been fully investigated; it is important to have more understanding of the influences of social networking sites in this region, particularly due to rapid expansion of online access. More young people coming online represents a higher level of risk being associated with them.

The perception of online risks for young people is often attributed to adult predators, whereas studies show that cyberbullies are likely to be in the same age group as their victims (Whitaker and Bushman, 2009). Managing such bullying is important as it can have a detrimental effect on young people (Whitaker and Bushman, 2009). It has also been found that $69 \%$ of UK adolescents regularly receive messages on social networking sites from people they do not know; they post personal information online, including photos, addresses and telephone numbers (Online Safety Site, 2014). Adult predators are not hiding their identity and the concern is that adolescents are willingly chatting with these adults, and in some cases even arranging to meet up with them offline (OSS, 2014). Although privacy settings are meant to protect young people, they often do not understand how to use them or are not concerned about giving out personal information (Wallbridge, 2009). This was found by Wallbridge to be a universal issue, as he studied online social networking sites from around the world, including Australia, USA, Japan, Brazil, India and Korea.

Livingstone and Helsper (2010) suggest that some activities which may be classified as risks are often seen as opportunities by UK adolescents; these include making new friends online, giving out personal information and viewing pornography. This overlap between opportunities and risks may need to be further defined, as it may also relate to the characteristics of the user and the potential harm which users may be caused. Concerns which adults may have towards adolescents using social networking sites may not present the risks that adults perceive. Sasson et al. (2011) focused on Israeli adolescents and how they perceived risks and found adolescents were aware of the risks and had mechanisms to deal with them; they did not consider cyberbullying to be a threat as it was in fact something they needed to deal with in real life and they viewed it as normal behaviour. There was a suggestion that online safety issues for adolescents were raised because the parents themselves did not know how to protect themselves online and they were transferring their fears onto their children (Sasson et al., 2011).

Increasingly, some governments, including the UK, are encouraging young people to participate in online activities as they see social media as a way of reducing costs, especially related to human resources, and widening access to information and awareness-raising services pertinent to young people (Robson, 2012). Popham (2010) argues that organisations connected with young people are reluctant to utilise social media as they are concerned about online safety and security of their young users. The main risks have been similar across Europe and continue to be seen as the disclosure of personal information, online bullying, pornography and violent, hateful or sexual content (Livingstone et al., 2011). It has also been found that those with learning difficulties are more likely to be at risk (Livingstone and Haddon, 2009) especially in terms of being more vulnerable to depression (McNamara et al., 2008) but young people themselves see the main risks as being identity theft and downloading viruses (Robson, 2012).

Robson (2012) investigated the aspect of safety online against the benefits for young people; she argues that the perception of risk on the part of parents may be greater than the actual risk involved. There is evidence that there is a difference between generations in the perception of risk (Healy and Sandra, 2007; HM Government, 2010) this can lead to parents not being aware of how young people use the internet. According to Robson (2012) those who use social media extensively tend to view it as beneficial and are more likely to be young people, whereas their parents are more likely to see the negative aspects of social media. Jenkins et al. (2009) argue that the skills needed to use the internet safely come from a combination of the technical skills found in young people aligned with the life skills of older age groups; for example, young people know how to use social media to gain information but they do not yet have the experience to differentiate between the genuine and the fraudulent. 


\section{Methodology}

This was an initial study relating to a wider research investigation of online behaviours of Gulf adolescents. The questionnaire to collect quantitative data from adolescents was designed using a mixture of multiple choice, a 5-part Likert scale and some closed question; at the end were 3 open questions. A survey was carried out by distributing questionnaires to young Gulf teenagers from Saudi Arabia, Bahrain and the UAE, who were attending an international school in the UK. The school facilitated the distribution and collection of paper-based surveys, once permissions had been received. Ethical approval was granted by the ethics committee of the University of Bedfordshire, and permissions were given by the Saudi Cultural Bureau as well as the school. In total, 115 completed responses were received from 150 questionnaires distributed. Of these 59 were females, 44 were males and 12 did not give their gender. All were aged between 13 and 18.

The results of the questionnaires were analysed manually, using statistical analysis to give an overall picture of the percentages involved. A summary sheet and simple coding frame were used for recording purposes, and these were then converted into charts. Where attitudes and opinions were elicited, the responses were initially listed, scanned for recurring themes and then content analysis procedures were applied; this involved establishing the frequency and placing them in context (Bell, 2006). This gave a foundation for identifying online behaviours of Gulf adolescents.

\section{Internet Usage}

The results of this survey showed that most young people are online several times a day. The length of time they were online varied, and what they were doing covered a wide range of activities. There was not much variation in the websites they had last visited, the main one being for educational purposes. No differences were noted in terms of gender, with both boys and girls accessing the same kinds of websites.

\section{Length of time spent online}

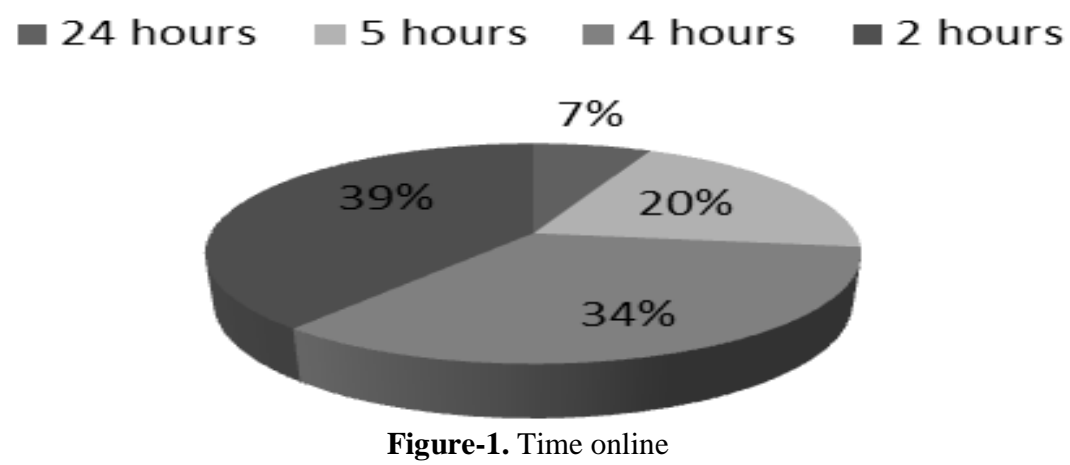

Most students (73\%) spent between two and four hours online each day, with quite a large number (20\%) spending on average five hours online (Figure 1). There were no differences noted between girls and boys. Some 7\% indicated that they never turned off and were available all the time. The main usage online was watching internet TV or movies. This was used by $70 \%$ of the students surveyed (Figure 2). Schoolwork also played an important part as $60 \%$ were online for this purpose, although it was closely followed by social networking. This compares with the UK where adolescents spend an average of 54 minutes per day on social networking sites (SNS), which $40 \%$ access every day (Rideout et al., 2010) UK adolescents spent at least 3 and a half hours per week on SNS, which is longer than the GCC teenagers. It may be that Gulf youngsters are still immature in their approach to such networking, being more bound by traditions of oral communication. Yet it must still be acknowledged that the UK is ahead of the Gulf States in terms of temporal digital experiences and this may nevertheless be an area where Gulf adolescents will follow. There is concern that the increasing amount of time that young people are online may lead to addiction, especially if the activities involved are social networking (Kuss and Griffiths, 2011).

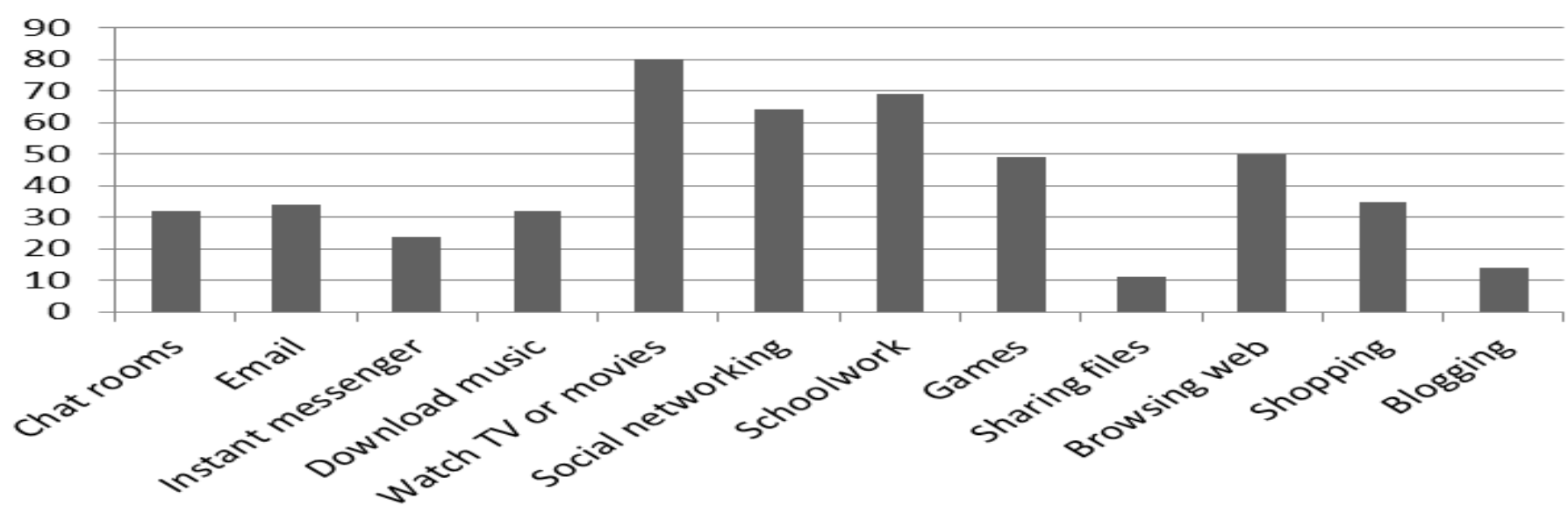

Figure-2. Activities carried out when online

Once the time spent online and the sort of websites visited was known, the survey looked at potential safety issues. These were mainly in connection with contacts made when online. Students were asked how safe they felt when connecting to the internet (Figure 3). As anticipated, most students felt unsafe when using either their own or someone else's device in the environment of a public place such as an internet café; it is noted that $38 \%$ felt safe 
using their own device. Not all students felt they were safe at home. Across all settings, whether on own device or someone else's device, there were some students who indicated that they did not feel safe when connecting to the internet.

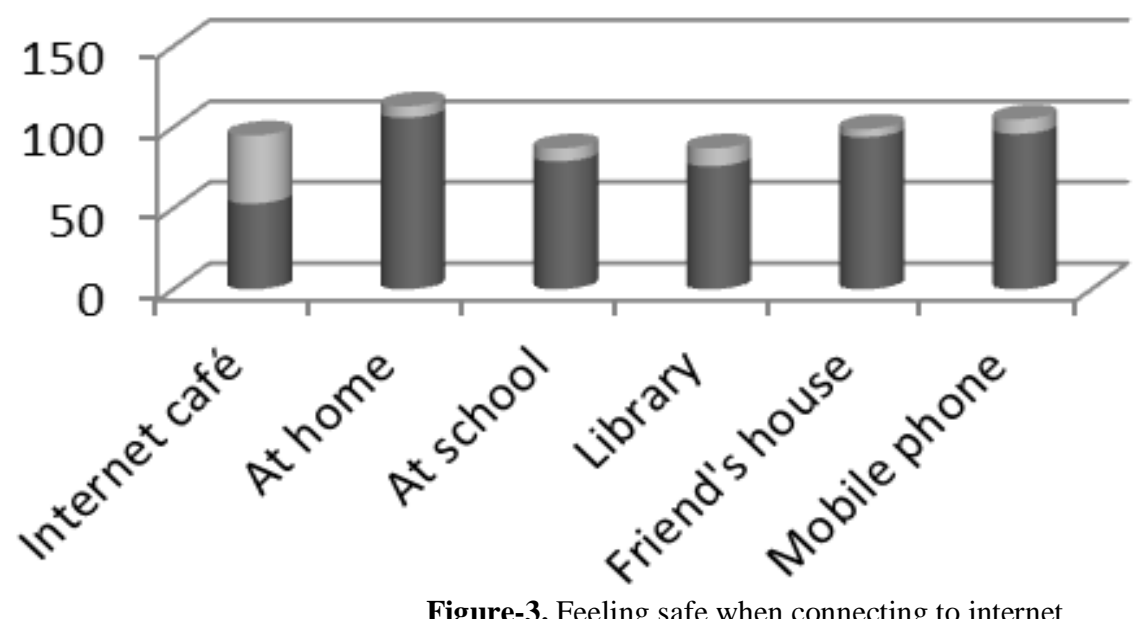

\section{Unsafe}

Safe

It was indicated that $75 \%$ of young people had received lessons on how to stay safe on the internet, mainly through their schools; nevertheless, $25 \%$ had had no such guidance. Participants were also asked where they received advice from regarding online safety (Table 1). This showed similarities to where they had received safety lessons, although there was now the dimension of own experience and own common sense, which may reflect the benefits of the lessons already received.

Table-1. Advice Regarding Online Safety

\begin{tabular}{l|l|l|l}
\hline Online & Parents & School & Family \& friends \\
\hline Trusted websites & Personal experience & YouTube & Common sense \\
\hline
\end{tabular}

Adolescents may also have contact online with people they have never met in real life, who are unknown to them. This may be a potential source of danger, but often depends on the virtual environment in which they are operating. When asked how many online contacts they had whom they had never met offline, $41 \%$ of students said they had none, although one student suggested they had about five hundred contacts. Other research shows that this is a potential risk and it supports existing literature indicating that $31 \%$ of American teens have online friends they have never met (Lenhart and Mary, 2007). 25\% of the adolescents did not respond to this question; this may be because they did not wish to disclose this information. While there may be a simple reason for this ommission, it could also be that they were in contact with undesirable people. A Newsbeat (2014) poll of UK teenagers stated that a third of UK teenagers had met in person with someone they had originally had contact with online. More recently, a report by Lenhart et al. (2015) for the Pew Research Centre found that $20 \%$ of American teenagers met up in person with friends they had met online, although $57 \%$ overall had made friends with someone online. This may be an indication of the Gulf adolescents also having such contact with strangers online. Although empirical research indicates that online communication is mainly used for keeping in contact with friends made offline, rather than to make new contacts (Gross, 2004; Boneva et al., 2006; Ellison et al., 2007; Mensch and Talmud, 2007; Valkenburg and Peter, 2007) there are still a significant number who are in contact with virtual strangers.

\section{Safety Issues}

In many cases there are ample opportunities for such strangers to identify and make contact with teenagers. A quarter of those surveyed had their own personalised webpage. Of these, most used their website to post photos of themselves or photos of their friends, and to provide information about their interests (Figure 4). Some of the adolescents provided their address and others gave the location of their school, both of which made it easy for others to identify their whereabouts. Apart from allowing others to identify where they lived and attended school, most young people used their own name when chatting, messaging and emailing (74\%). They also stated which websites they used when identifying themselves, with $61 \%$ saying they gave their real name when using the sites, although seven adolescents admitted to pretending to be someone else when chatting, emailing or messaging.

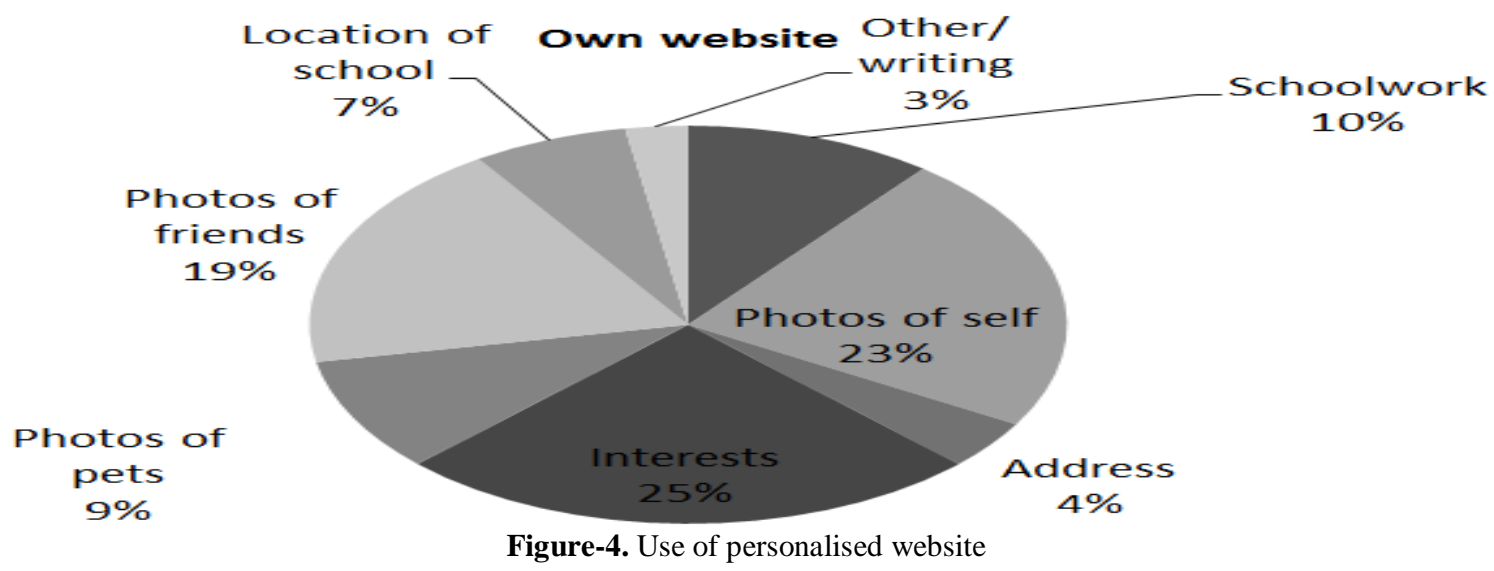


In response to the question: "Have you ever become romantically involved with someone you have only met online?" $72 \%$ gave a negative answer. A considerable number did not wish to say, whereas $3 \%$ of young people declared that they had. Although 63\% stated that they had never arranged to meet someone in real life whom they had first met through chat or instant messaging, a further $20 \%$ declined to answer the question. This could again be a simple omission, or due to cultural sensitivities, but it could also indicate that they did not want others to know that they had done so; $17 \%$ admitted to having made such arrangements, and they said that they had told friends, parents or a sister.

When asked to name three things they believed would keep them safe online, it was interesting to note that many of the responses were perhaps ones where they may have thought they were saying the right thing, having had safety lessons. These did not necessarily relate to the answers they had already given on their actual usage when online. For example, responses seemed to reiterate advice they had been given on not disclosing any personal information or meeting up in person with people they did not know. There were also responses about security measures when using the computer, such as not downloading anonymous files or going on suspicious websites. Advice was also given on using parental controls and a good antivirus programme.

Responses about unsafe things online showed that there was a good understanding of potential risks coming from financial transactions and advertisements. There was also awareness of the risks of viruses, being hacked and connections in internet cafes. Cyberbullying and fake identities were mentioned and Kik was named as being a site where people could add you without a request message. Although Ybarra and Mitchell (2008) found that instant messaging and chatrooms were high risk in terms of cyberbullying, there was no indication that participants regarded these as unsafe areas.

Some of the additional responses were thoughtful and addressed new areas. One respondent said:

"I think a lot of children use illegal websites to download unpaid online services, because almost all online services are paid using credit cards so they go to the illegal websites to get the services for free. This could lead to a lot of danger to the child including hacking and bullying. I think companies should think of more ways to pay online, like gift cards, for children's safety."

There was also concern that perhaps the internet should be more age-restricted: "Young people shouldn't be using it at a young age at all. Make sure you know who you are talking to". Some wanted more support from parents: "The internet is really unsafe so don't make it easy for children to use, or try checking on the use every day", and "Parents, especially fathers, are in urgent need of being trained on children's use of the internet", "If children are doing bad or good things, it is because of their parents".

\section{Conclusion}

These findings provide evidence of the way these adolescents from the GCC countries use the internet and their perceptions of safety online. They spend a number of hours online every day and mainly use the internet several times a day. The predominant usage was watching movies, though this was followed by schoolwork, and educational websites were most popular. It is seen that the young people in the Gulf States differ from their UK counterparts in their type of usage; British youngsters have more experience in social networking skills. There is consequently an expectation that Gulf adolescents may follow this trend over time, and it may be a good opportunity at this stage to consider some interventions that may prevent future negative connotations associated with social networking safety.

For the most part, adolescents were getting advice on internet safety and much of this came from their schools, but a quarter had never had any advice and guidance on keeping safe online. Their perceptions of safe internet usage showed that they did not in general trust internet cafes. Mobile phones and texts remain their most important way of contacting friends and most used their own identity when in contact with friends. In the UK there are numerous online websites where young people may obtain advice about online usage and behaviour; although there may be no indication of how successful overall these sites may be, it is clear that some young people find these useful. Setting up trusted websites, which can be signposted by schools and others giving advice and guidance, may be a safety net for some vulnerable youngsters.

A large number had at some stage allowed their passwords to be used by others, although this was one of the points they made about it not being safe. There were various opinions as to what kept them safe online or what may be regarded as unsafe. A significant comment was that adolescents are aware that their parents may not understand this technology and perhaps need further training. This indicates that these young people still value the support and guidance of their parents, and there may yet be a bigger role that parents have to play in keeping their children safe online. It may be that more resources need to be allocated to awareness programmes for parents, so that they can understand and support their youngsters as they explore this new technology.

\section{References}

Bell, J., 2006. Doing your research project. 4th Edn., Maidenhead: Open University Press

Boneva, B., A. Quinn, R. Kraut, S. Kiesler and I. Shklovski, 2006. Teenage communication in the instant messaging Era. In R.Kraut, M.Brynin \& S. Kiesler (Eds), Computers, phones and the internet: Domesticating information technology. Oxford: Oxford University Press.

Ellison, N., C. Steinfield and C. Lampe, 2007. The benefits of facebook 'friends: Social capital and college students' use of online social network sites. Journal of Computer-Mediated Communication, 12(4): 1143-1168. View at Google Scholar $\mid$ View at Publisher

Gross, E.F., 2004. Adolescent internet use: What we expect, what teens report. Applied Developmental Psychology, 25(6): 633-649. View at Google Scholar $\mid$ View at Publisher

Healy, J. and A. Sandra, 2007. Children and young people's use of technology. Methodology, 2: 5.

HM Government, 2010. Positive for youth: A new approach to cross-government policy for young people aged. 13 - 19. Retrieved from https://www.gov.uk/government/publications/positive-for-youth-a-new-approach-to-cross-government-policy-for-young-peopleaged-13-to-19 [Accessed 25 August, 2014].

Jenkins, H., R. Purushotma, M. Weigel, K. Clinton and A.J. Robison, 2009. Confronting the challenges of participatory culture media education for the 21st century. Massachusetts: MIT Press.

Jurgenson, N., 2010. The De-McDonaldization of the internet. In G. Ritzer (Ed), McDonaldization the reader. 3rd Edn., Thousand Oaks, CA: Pine Gorge Press. 
Kuss, D.J. and M.D. Griffiths, 2011. Excessive online social networking: Can adolescents become addicted to facebook? Education and Health, 29(4): 63-66. View at Google Scholar

Lenhart, A. and M. Mary, 2007. Teens, privacy and online social networks: How teens manage their online identities and personal information in the age of myspace.

Lenhart, A., A. Smith, M. Anderson, M. Duggan and A. Perrin, 2015. Teens, technology and friendships.

Lin, K.Y. and H.P. Lu, 2011. Why people use social networking sites: An empirical study integrating network externalities and motivation theory. Computers in Human Behaviour, 27(3): 1152-1161. View at Google Scholar $\mid$ View at Publisher

Livingstone, S. and L. Haddon, 2009. EU kids online: Final report. LSE London: EU Kids Online.

Livingstone, S., L. Haddon, A. Gorzig and K. Olafsson, 2011. Risks and safety on the internet: The perspective of European children. LSE London: EU Kids Online.

Livingstone, S. and E.J. Helsper, 2010. Balancing opportunities and risks in teenagers' use of the internet: The role of online skills and internet self-efficacy. New Media and Society, 12(2): 309-329. View at Google Scholar| View at Publisher

McNamara, J., S. Vervaeke and T. Willoughby, 2008. Learning disabilities and risk taking behaviour in adolescents: A comparison of those with and without comorbid attention-deficit/hyperactivity disorder. Journal of Learning Disabilities, 41(6): 561 574. View at Google Scholar $\mid$ View at Publisher

Mensch, G.S. and I. Talmud, 2007. Similarity and the quality of online and offline social relationships among adolescents in Israel. Journal of Research on Adolescence, 17(2): 455-465. View at Google Scholar $\mid$ View at Publisher

Moreno, M.A., K.G. Egan, K. Bare, H.N. Young and E.D. Cox, 2013. Internet safety education for youth: Stakeholder perspectives. BMC Public Health, 13(1): 543. View at Google Scholar | View at Publisher

Newsbeat, 2014. 1 in 3 teenagers meet social media 'friends' in real life. Retrieved from http://www.bbc.co.uk/newsbeat/article/29457870/1in-3-teenagers-meet-social-media-friends-in-real-life [Accessed 14 October, 2016].

Online Safety Site, 2014. Teen internet statistics. Retrieved from http://www.onlinesafetysite.com/P1/Teenstats.htm [Accessed 19 October, 2014].

OSS, 2014. Teen internet statistics. Retrieved from http://www.onlinesafetysite.com/P1/Teenstats.htm [Accessed 19 October, 2014].

Popham, 2010. New ways of delivering services for young people. RYWU-NE Annual Conference, Newcastle upon Tyne, October 2010.

Rideout, V., 2012. Social media, social life: How teens view their digital lives. San Francisco: Common Sense Media.

Rideout, V.J., U.G. Foehr and D.F. Roberts, 2010. Generation M2: Media in the lives of 8 to 18 year olds. Menlo Park, CA: Kaiser Family Foundation.

Robson, L., 2012. Internet safety and young people. Newcastle: Regional Youth Work Unit North East.

Sasson, H., R. Erez and Z. Elgali, 2011. Risks on the web: Adolescents' perceptions and coping mechanisms. 4th Knowledge Cities World Summit, Brazil 26-27 October, 2011.

Valkenburg, P.M. and J. Peter, 2007. Internet communication and its relation to well-being: Identifying some underlying mechanisms. Media Psychology, 9(1): 43-58. View at Google Scholar | View at Publisher

Wallace, K., 2013. The upside of selfies: Social media isn't all bad for kids. CNN International, 22 November, 2013.

Wallbridge, R., 2009. How safe is your facebook profile? Privacy issues of online social networks. ANU Undergraduate Research Journal, 1(0): 1-8. View at Google Scholar

Whitaker, J.L. and B.J. Bushman, 2009. Online dangers: Keeping children and adolescents safe. Washington: Lee Law Review, 66.

Ybarra, M.L. and K.J. Mitchell, 2008. How risky are social networking sites? A comparison of places online where youth sexual solicitation and harassment occurs. Pediatrics, 121(2): e350-e357. View at Google Scholar $\mid$ View at Publisher 